\title{
Paper and Water: cómo acercar la ciencia a la práctica de la restauración
}

\author{
Salvador Muñoz Viñas
}

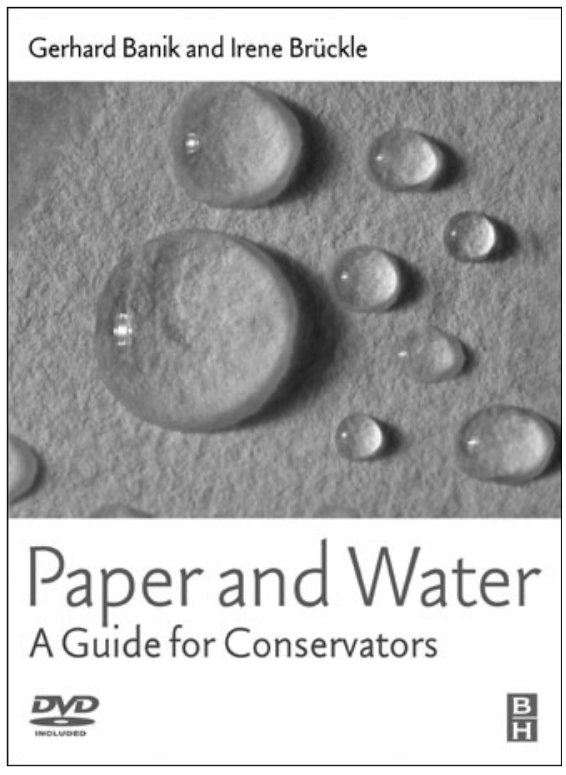

Portada de Paper and Water. A Guide for Conservators, Gerhard Banik e Irene Brückle (eds.), 2011, Ámsterdam, Elsevier/ButterworthHeinemann.
S e ha hablado, y mucho, de la relación entre la ciencia y la restauración. En algunos casos, se elogian de manera apasionada los beneficios que las técnicas de indagación científica aportan a la última: según tal enfoque, el rigor de los sofisticados sistemas de análisis propios de las ciencias materiales (la química, la física, incluso la biología), es fundamental para el quehacer de la restauración, disciplina que proviene de ámbitos puramente artesanales $y$, demasiado a menudo, es desarrollada por profesionales con conocimientos limitados. Ese apoyo científico, en teoría, le confiere a la práctica del restaurador una solidez intelectual que la dignifica, la eleva por encima de la pura actividad manual, y la mejora de muchas maneras. ${ }^{1}$

En sentido contrario, muchos restauradores se han quejado de que la mayor parte de la ciencia aplicada a la restauración no es realmente aplicable. Según esta visión, la ciencia a menudo funciona como un mero artificio decorativo para la restauración cuya misión consiste en proveerle de una apariencia de naturaleza científica que no corresponde con la realidad. También es habitual oír quejas sobre cómo los científicos trabajan al margen del profesional de la restauración: es imposible no constatar que tanto los objetivos como los logros de muchas de las investigaciones realizadas por los primeros son de hecho irrelevantes en la práctica real de los restauradores. Para agravar el problema, la presentación de los trabajos científicos se hace frecuentemente con lenguajes y protocolos propios de disciplinas ajenos a la restauración, de modo que, según se suele comentar, no son siquiera inteligibles para los profesionales que deberían beneficiarse de ellos. Como ha señalado Gael de Guichen (1991), los científicos de la restauración se asemejan con frecuencia a satélites que se han salido de la órbita y que, alejándose progresivamente de la Tierra, emiten mensajes cada vez más incomprensibles. ${ }^{2}$

\footnotetext{
${ }^{1}$ El lector interesado encontrará un listado de referencias sobre este tema en Contemporary Theory of Conservation (Muñoz Viñas 2002). Para un análisis más amplio sobre este enfoque véase Muñoz Viñas (2004: 81-90).

${ }^{2}$ El capítulo 5 de Contemporary Theory of Conservation (Muñoz Viñas 2004: 115-146) presenta una reflexión y un listado de literatura sobre esta temática.
} 
En definitiva, la "gran división" (the great divide) entre científicos y restauradores de la que hablaba Mary Striegel (en McCrady 1997: 243) existe, y sigue siendo un problema en el mundo de la conservación. Desgraciadamente, no todos están dispuestos a modificar su postura ni a tender puentes ni a moverse hacia el otro lado a través de ellos. A causa de su rareza, cuando este tipo de esfuerzos de aproximación se hace desde la honestidad intelectual, y con la voluntad sincera y eficaz de tender esos lazos, los profesionales de la restauración debemos ofrecerles la bienvenida que merecen. Es ésta la razón primordial que me ha llevado a escribir la reseña de Paper and Water: A Guide for Conservators (Banik y Brückle 2011).

El libro, una recopilación de textos coordinada y editada por los profesores Gerhard Banik e Irene Brückle, quienes lo escribieron junto con otros nueve autores, está destinado a convertirse en un clásico en el ámbito de la restauración del papel, no sólo porque trata un tema crucial acerca del que no existía ninguna monografía comparable, sino también - quizá sobre todo- por la voluntad de comunicar asuntos de manera efectiva.

Gerhard Banik empieza el libro con una introducción a los principios básicos de química: su desarrollo es muy bueno tanto por la selección de contenidos (sólo se mencionan aquellos que realmente interesan) como por la manera en la que acierta a describirlos. Estas 80 páginas iniciales, aunque no sustituyen a un curso de química, sin duda resultarán un eficaz recordatorio para un restaurador con formación media o universitaria.

Los tres siguientes capítulos describen las propiedades físicas del papel en relación con su composición y proceso de fabricación. Aunque desgraciadamente Irene Brückle y los dos autores restantes no enfatizan las consecuencias de estos aspectos para la conservación y la restauración del papel, una vez más, la manera de presentarlos y la selección de la información son óptimas, en tanto que muestran de manera muy evidente muchas facetas del comportamiento del papel antes y durante el tratamiento de restauración. Para un restaurador, estos capítulos son enormemente aconsejables.

El capítulo 8, escrito por Paul Whitmore, es otra pequeña joya, porque explica de manera brillante el proceso químico de envejecimiento del papel y los efectos del agua sobre éste. En los capítulos siguientes, Gerhard Banik, Irene Brückle y Vincent Daniels explican cómo penetra el agua en el papel, y su efecto disolvente sobre los productos del envejecimiento. Aunque, sin duda, los restauradores con cierta experiencia tenemos un conocimiento práctico o intuitivo de estos mecanismos que ningún texto puede sustituir, los principios expuestos en estos capítulos de Paper and Water completarán y consolidarán nuestro saber $y$, como el resto del libro, a un restaurador joven y mínimamente inquieto le ahorrarán buena parte de los procesos de prueba-y-error, a través de los cuales muchos hemos adquirido nuestras habilidades.

Los capítulos 11 y 13, escritos por Joana Kosek, Irene Brückle y Gerhard Banik, son particularmente interesantes porque describen técnicas de baño y alisado; algunas de ellas seguramente serán conocidas para el lector, pero también se describen otras, como el baño por flotación, la limpieza por capilaridad o el alisado por falsos márgenes, que son menos comunes, de modo que su lectura constituye toda una incitación a la experimentación. Como siempre en este volumen, el apoyo de las fotografías y esquemas es excelente, y compensa con éxito el lenguaje rápido y un poco sumario con que se tratan estos temas.

El último capítulo del libro, una reflexión de Irene Brückle sobre el efecto sobre el papel de los tratamientos acuosos de restauración, debería ser de lectura obligatoria para todos los profesionales y estudiantes de restauración, porque nos recuer- da cómo incluso operaciones tan habituales como el baño o el alisado pueden llegar a afectarlo negativamente: leerlo nos hará más sabios, más prudentes, o más decididos, si se hace necesario.

Paper and Water concluye con una abundante serie de apéndices, que incluyen una tabla de unidades de medida, una serie de experimentos docentes y un glosario. En la guarda trasera se aloja un DVD que contiene varias películas y animaciones que ilustran algunos de los aspectos tratados en el libro.

Ciertamente, la mayor parte de la información presentada en esta obra ya se ha publicado en revistas especializadas, o difundido en cursos de especialización: la bibliografía que sigue a cada capítulo así lo testimonia, $y$, por lo tanto, no hay ninguna pretensión de novedad. Sin embargo, la oportunidad de disponer de esta información en un solo volumen, $y$ en un lenguaje claro y asequible, hace que este libro sea especialmente valioso. Sencillamente, no existen obras en las que se hayan tratado estos temas desde tal punto de vista y con semejante profundidad. Algunos textos clásicos de restauración del papel, como los de Crespo y Viñas (1984), Federici y Rossi (1983) o Lienardy y Van Damme (1989), por ejemplo, no abordan las cuestiones tratadas en Paper and Water más que de forma muy fragmentaria, si es que las abordan en absoluto. Otros textos, como los de Martin (1965), Copedè (1995), Zappalà (1990) o el del autor de esta reseña (Muñoz Viñas 2010), contienen más información sobre las interacciones entre el agua y el papel, pero no se comparan en este sentido con una monografía de casi 600 páginas como Paper and Water.

Esto no es propiamente una crítica a esas obras, cuyos objetivos son distintos del de Paper and Water: se trata - a excepción de los libros de Copedè (1995) y Martin (1996) — de manuales de restauración en los que se describen los procedimientos y las recetas que los autores consideran más relevantes. Recíprocamente, se 
debe aclarar que la obra que nos ocupa no es un libro de recetas ni de instrucciones: lo cual tampoco es una crítica, puesto que su fin no consiste en que el lector aprenda las técnicas mencionadas, dispersas sobre todo en los últimos capítulos, sino que comprenda cómo el agua, en todas sus formas, afecta al papel. El restaurador quizá hubiera agradecido una descripción más detallada de todas las técnicas mencionadas en el texto, tal y como se hace en un manual de restauración. Pero Paper and Water no lo es, y que el lector lo tenga claro es importante porque, en caso contrario, le resultará frustrante no hallar, por ejemplo, las instrucciones detalladas del sistema de lavado por lámina capilar o de cualquier otra técnica de restauración del papel a las que se alude a lo largo del texto. El objetivo del libro $-y$ creo sinceramente que lo alcanzaes permitirnos entender las importantísimas y complejas interacciones entre el agua y el papel durante su proceso de envejecimiento o durante su restauración.

Así, la lectura de esta obra, aunque quizá no nos enseñe a restaurar, sí que nos enseñará a restaurar mejor, porque nos hará capaces de prever los resultados de ciertas acciones (o inacciones), $y$, por lo tanto, de tomar decisiones de manera más informada: es una satisfacción poder decir que la "gran división" de la que hablaba Striegel es ahora un poquito más pequeña.

\section{Referencias}

Banik, Gerhard e Irene Brückle (eds.) 2011 Paper and Water. A Guide for Conservators, Ámsterdam, Elsevier/ Butterworth-Heinemann.

Copedè, Maurizio 1991 La carta e il suo degrado, Florencia, Nardini.

Crespo, Carmen y Vicente Viñas 1984 La preservación y restauración de documentos y libros en papel, París, UNESCO.

Federici, Carlo y Libero Rossi 1983 Manuale di conservazione e restauro del libro, Roma, Carocci.

Guichen, Gael de 1991 "Scientists and the preservation of cultural heritage", en N. S. Baer, C. Sabioni y André I. Sors (eds.), Science, Technology and European Cultural
Heritage: Proceedings of the European Symposium, Bolonia, 13-16 de junio de 1989, Oxford, Butterworth-Heinemann, 17-26.

Liénardy, Anne y Philippe Van Damme 1989 Inter Folia. Manuel de conservation et de restauration de papier, Bruselas, Institut Royal du Patrimoine Artistique.

Martin, Gerard 1965 Físico-química del papel, BarceIona, Publicaciones Offset.

McCrady, Ellen 1997 "Can scientists and conservators work together?", en Susan Bradley (ed.), The Interface Between Science and Conservation, Londres, British Museum, 243-247.

Muñoz Viñas, Salvador 2002 "Contemporary Theory of Conservation", Reviews in Conservation 3: 25-34.

2004 Contemporary Theory of Conservation, Oxford, Elsevier/ButterworthHeinemann.

2010 La restauración del papel, Madrid, Tecnos.

Zappalà, Antonio 1990 Introduzione agli interventi di restauro conservativo di beni culturali cartacei, Udine, Del Bianco.

Título en inglés: Paper and Water: How to Bring Science Closer to Conservation ractice 